\title{
Regeneration of Indian maize genotypes (Zea mays $L$.$) from immature embryo$ culture through callus induction
}

\author{
N. Malini*1, C. R. Ananadakumar ${ }^{2}$ and S. Hari ramakrishnan ${ }^{3}$ \\ ${ }^{1}$ ARS, Kovilpatti, Tamil Nadu Agricultural University, Coimbatore, INDIA \\ ${ }^{2}$ Centre for Plant Breeding and Genetics, Tamil Nadu Agricultural University, Coimbatore, INDIA \\ ${ }^{3}$ Agricultural College and Research Institute,Tamil Nadu Agricultural University, Coimbatore, INDIA \\ *Corresponding author. E-mail: malinipbg200201@gmail.com
}

Received: September 12, 2014; Revised received: February 28, 2015; Accepted: March 19, 2015

\begin{abstract}
Callus induction and regeneration ability of five maize genotypes UMI 757, UMI 615, UMI 112 , UMI 285 and $\mathrm{CO} 1$ and one promising maize hybrids $\mathrm{COH}(\mathrm{M}) 5$ were investigated using 14 days old immature embryos as explants. Callus induction depends on genotype, explants (age and size of explants), medium, type of auxin and their concentration. Explants grown on Murashige and Skoog (MS) medium supplemented with 1.5 mg/l 2, 4 - D (2,4 - dichloro phenoxy acetic acid), $0.3 \mathrm{mg} / \mathrm{l}$ kinetin with $30 \mathrm{~g} / \mathrm{l}$ maltose showed the highest percentage of embryogenic callus induction. Among the six genotypes tested, $\mathrm{COH}(\mathrm{M}) 5$ maize hybrids have highest percentage of embryogenic calli. The embryogenic calli incubated on MS medium supplemented with $1.5 \mathrm{mg} / \mathrm{l}$ BAP (Benzyl Amino Purine), $0.2 \mathrm{mg} / \mathrm{l}$ NAA (Naphthalene Acetic Acid) with $1.0 \mathrm{mg} / \mathrm{l}$ kinetin was found to give the highest organogenesis response and regeneration of plantlets.
\end{abstract}

Keywords: Callus induction, Immature embryo, Maize, Regeneration

\section{INTRODUCTION}

Maize (Zea mays L.) is the most important cereal crop in the world in terms of global annual tons produced (FAO, 2009). It is raw material for a number of industrial products besides its uses as human food and animal feed. At present, the developed world uses maize more than the developing world, but forecasts indicate that by the year 2020, the developing countries will demand more than the developed world (Duvick, 1998). Hence, it is time to embrace fast, effective and reliable techniques like biotechnology, in maize improvement programme to ensure sufficient production (Machuka, 2001 and Pingali and Pandey, 2001). One such technique is genetic transformation. The success of any transformation work depends on culture, duration and efficiency of the regeneration system. Green and Philips (1975) reported regeneration of maize from immature embryo for the first time. Since then, maize tissue culture and transformation has involved the use of immature zygotic embryos as an explants source for regeneration (Ishida et al., 1996; Shohael et al., 2003; Danson et al., 2006; Aguado Santacruz et al., 2007; Manivannan et al., 2010; Rakshit et al., 2010), mature embryos (Huang and Wei, 2004; Al- Abed et al., 2006; Abebe et al., 2008), nodal regions (Vladimir et al., 2006), leaf tissues (Ahmadabadi et al., 2007), anthers (Barloy and Beckert, 1993), tassel and ear meristem (Pareddy and Petolino, 1990), Protoplast (Morocz et al., 1990) and shoot meristem (Sairam et al., 2003). Immature embryos are predominantly used for establishing regeneration competent cells (or) callus cultures for genetic transformation (Ahmadabadi et al., 2007). First developed transgenic maize for bialophos resistance (Gordon- Kamm et al., 1990). First time developed insect resistant transgenic maize with cry 1 Ab (Koziel et al., 1993). However, maize genotypes adapted to temperate regions have been used in these studies on regeneration and transformation (Bohorova et al., 1995). To harness the benefits of genetic transformation in breeding programme under tropical and sub-tropical Indian climatic conditions, it is important to develop protocols of regeneration and transformation for Indian maize inbreds. Therefore, the objectives in the present study were to establish a reproducible regeneration protocol for well adapted Indian maize genotypes and hybrid and also to compare the efficiency of different sources of auxins on callus induction and regeneration capacity.

\section{MATERIALS AND METHODS}

Plant materials and embryo excision: Five well adapted Indian maize genotypes such as UMI 757, UMI 615, UMI 112, UMI 285 and CO 1 and one hybrid $\mathrm{COH}$ (M) 5 were used in the study. These lines were planted in the Botany farm of Agricultural College and Research Institute, Tamil Nadu Agricultural University, Madurai. Pollination was controlled by covering the sprouting ears with transparent polythene bag. Plants were self pollinated and the whole ears were collected at 14 Days After Pollination (DAP) for subsequent 
tissue culture experiment according to Ishida et al., 1996. Immature embryo has proven to be the best source for the establishment of embryogenic callus and plant regeneration in maize. The immature embryo from immature cob were collected at 14 days after pollination, explants were excised only from healthy plant. The kernel were surface sterilized with $70 \%$ ethanol for 2 minutes followed by $0.1 \% \mathrm{HgCl}_{2}$ for 5 min and then washed with three to four times with sterilized distilled $\mathrm{H}_{2} \mathrm{O}$, under aseptic conditions. Under laminar Air Flow chamber, the immature embryos were aseptically excised from the kernel of the ears by cutting off kernel using scalpel blade and removing the endosperm. Immature embryos of $1.0-2.0 \mathrm{~mm}$ size were aseptically excised from surface sterilized kernels. The immature embryos were placed on the semisolid MS medium (Murashige and Skoog, 1962) with the rounded scutellar side exposed and the flat plumule-radical axis side in contact with the medium.

Callus induction: Different media (MS and N6) were used for callus induction supplemented with $1.5 \mathrm{mg} / \mathrm{l}$ 2,4 - dichloro phenoxy acetic acid (2,4- D) with 0.3 $\mathrm{mg} / \mathrm{l}$ kinetin with $\mathrm{pH}$ adjusted to 5.8 prior to autoclaving at $121^{\circ} \mathrm{C}$ for $15-20 \mathrm{~min}$. Thirty explants per treatment were taken in three replications. Explants were incubated in dark for 24 hour at $28^{\circ} \mathrm{C}$. Then these were transferred to 16 hour photoperiod, $50-70 \mu \mathrm{E} / \mathrm{m}^{2} / \mathrm{s}$ light intensity. After two weeks, number of explants producing primary callus were recorded, calli were subculture on to fresh medium of the same composition after 15-20 days.

Regeneration: After one month, the embryogenic calli transferred on to maturation medium for three weeks. Every ten days, the regenerated calli were sub cultured on fresh medium. The calli were transferred on regeneration medium with out any hormones for two weeks. After two weeks, the calli were transferred on to different shooting medium. After 10 days they were transferred on to rooting medium (MS+ with out hormone) for one week. Plantlets with well developed roots were transferred overnight to half strength liquid MS medium ( $\mathrm{pH}$ 5.8) with out sucrose and then transferred to pots containing sterilized soil for acclimatization, under 16 hour photoperiod for seven days following acclimatization, plants were moved to the green house for further growth.

The observations recorded were statistically analyzed by subjecting the data to Factorial Completely Randomized Design, designed by (Gomez and Gomez, 1984). Level of significance was determined by using standard analysis of variance. Differences among mean values were assessed by LSD. The data obtained with per cent values were subjected to arc sine transformation.

\section{RESULTS AND DISCUSSION}

An efficient regeneration protocol is prerequisite to a successful genetic transformation work in any crop plant. Maize genotypes have profound differences for in vitro culture and only a small number of maize genotypes posses regeneration capacity. Hence, it becomes important to specify growth condition for specific genotypes under in vitro culture to exploit potential tools of in vitro culture such as doubled haploid, somaclonal variation and genetic transformation. Many reports are available in maize suggesting successful regeneration from mature embryos (Huang and Wei, 2004), nodal culture (Vladimir et al., 2006), split seeds (Al-Abed et al., 2006) and immature embryos as explants (Duncan et al., 1985; Furini and Jewell, 1994 and Bohorova et al., 1995). The present work focuses on devising a standard protocol for regeneration of tropical Indian maize inbreds. Therefore, we made an effort to obtain regeneration using immature embryo as best explants in maize. Towards this endeavour we principally followed the protocols suggested by (Bohorova et al., 1995), who reported that N6 medium containing Dicamba and $\mathrm{AgNO}_{3}$ give efficient callus induction and plant regeneration in tropical and sub tropical maize germplasm. The role of 2,4-D with MS media in inducing highly regenerable calli from mature embryos (Huang and Wei, 2004). Successful regeneration from immature embryos using MS supplemented with 2,4-D reported by (Rooz, 2002). Thus, we made an effort to induce regeneration in Indian maize using both MS and N6 media supplemented with 2,4-D and kinetin.

Callus induction: Based on analysis of variance, all

Table 1. Effect of media on callus induction per cent in immature embryo culture (expressed in per cent).

\begin{tabular}{|c|c|c|c|c|c|c|c|c|}
\hline \multirow{2}{*}{$\overbrace{\text { Genotypes }}^{\text {Media }}$} & \multicolumn{4}{|c|}{$\begin{array}{c}\mathbf{M S}+\mathbf{1 . 5} \mathrm{mg} \mathrm{l}^{-1} \mathbf{2 , 4 - D}+\mathbf{0 . 3} \mathrm{mg} \mathrm{l}^{-1} \mathbf{K}+ \\
30 \mathrm{~g} \mathrm{l}^{-1} \text { sucrose }\left(\mathbf{S}_{1} \mathbf{D}_{1} \mathbf{K}_{1}\right)\end{array}$} & \multicolumn{4}{|c|}{$\begin{array}{c}\mathbf{N}_{6}+1.5 \mathrm{mg} \mathrm{l}^{-1} \\
30 \mathrm{~g} \mathrm{l}^{-1} \text { sucrose }\left(\mathbf{N}_{6}\right)\end{array}$} \\
\hline & A & B & $\mathbf{C}$ & D & A & B & $\mathrm{C}$ & D \\
\hline$\left(\mathrm{G}_{1}\right)$ UMI 757 & 84.96 & 70.16 & 14.78 & 39.32 & 67.13 & 62.71 & 21.75 & 19.82 \\
\hline (G2) UMI 615 & 86.62 & 72.16 & 15.52 & 45.16 & 76.89 & 63.83 & 28.03 & 26.25 \\
\hline$\left(\mathrm{G}_{3}\right)$ UMI 112 & 85.13 & 71.15 & 16.50 & 40.10 & 77.01 & 64.88 & 19.54 & 27.86 \\
\hline$\left(\mathrm{G}_{4}\right) \mathrm{COH}(\mathrm{M}) 5$ & 88.75 & 75.22 & 13.28 & 47.26 & 68.15 & 63.50 & 26.15 & 25.12 \\
\hline$\left(\mathrm{G}_{5}\right) \mathrm{UMI} 285$ & 78.45 & 66.43 & 18.22 & 35.33 & 51.74 & 42.26 & 37.24 & 15.16 \\
\hline (G6) CO 1 & 65.71 & 61.52 & 23.42 & 19.42 & 80.06 & 67.67 & 18.03 & 30.96 \\
\hline
\end{tabular}

Callus induction (A), embryogenic callus formation (B), rhizogenic callus formation (C) and regeneration (D) 


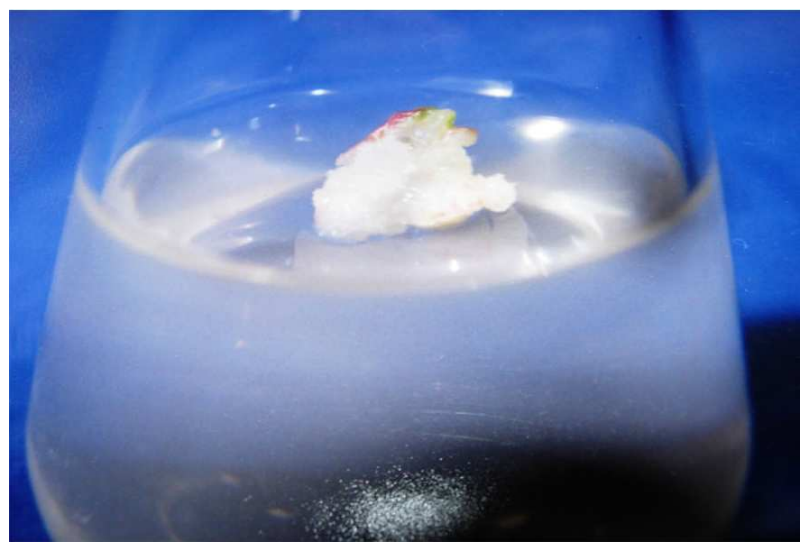

(a) Callus induction from immature embryo on $\mathrm{COH}(\mathrm{M}) 5$

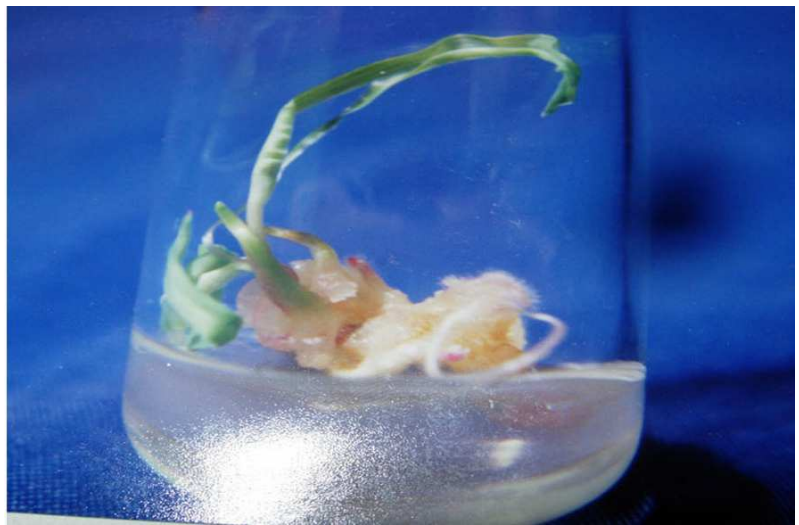

(c) organogenesis from immature embryo

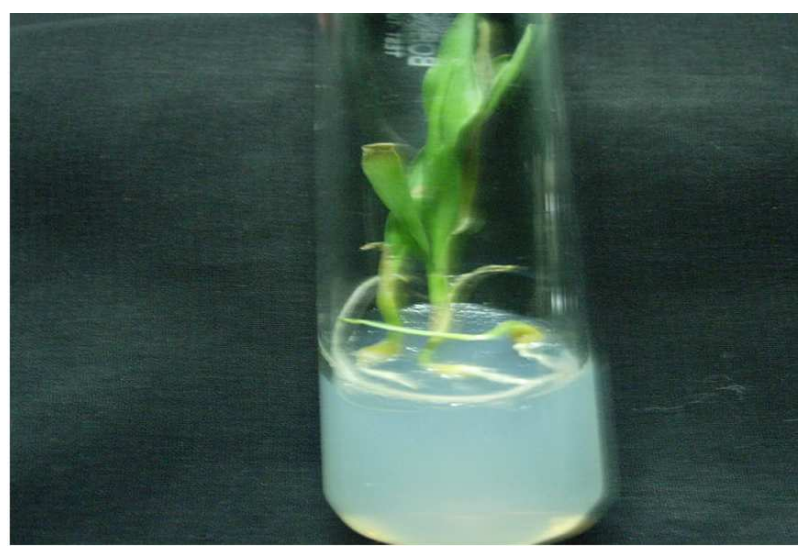

(e) Regenerated plantlets on rooting media

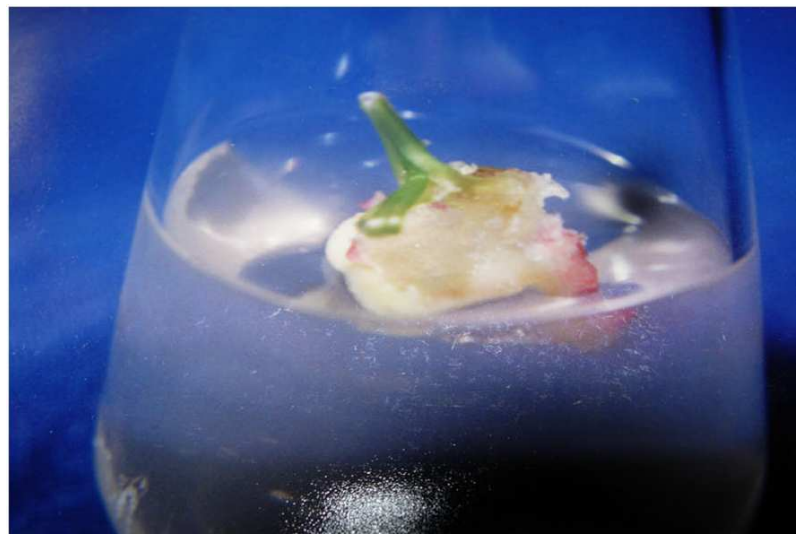

(b) Emergence of green spot from embryogenic callus

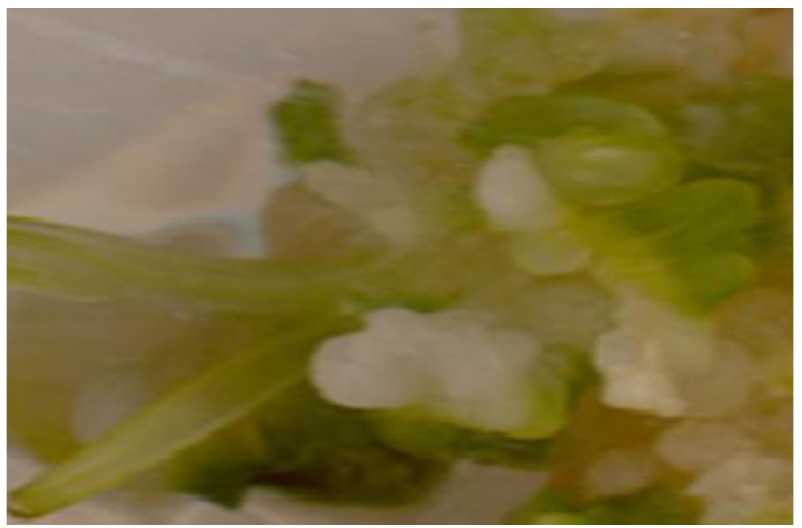

(d) Regenerated plant

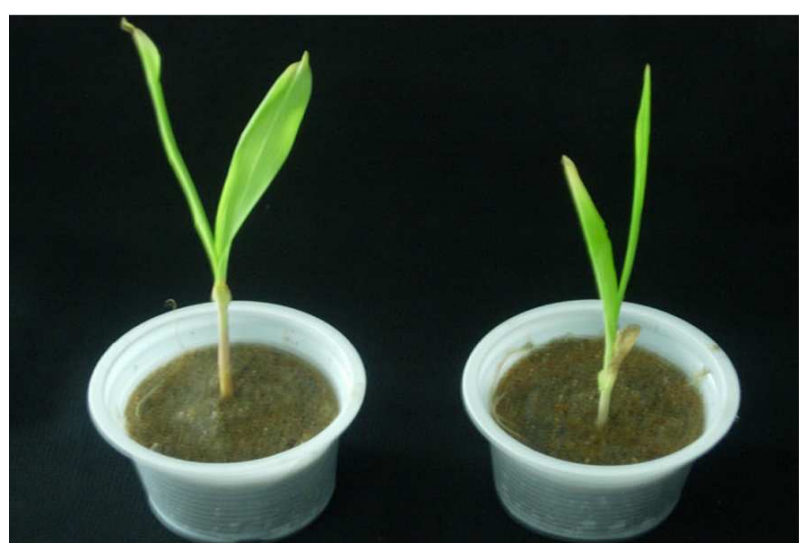

(f) Hardening plant in plastic cups

Fig. 1. Regeneration of plants from immature embryo culture.

the four parameters, including genotype, induction medium, type of auxin and level of auxin influenced the frequency of callus induction. The mean callus induction percentage was higher on MS media ranged from 65.71 to 88.75 compared to N6 media. Callus intiation from cultured embryos was observed with in one weed following culture, with swelling of the scutellum and formation of mass on the surface of scutellum. Within 15 days of incubation, the swollen scutellum developed in to irregular callus, which turned in to organogenic callus after an additional 15 days. The embryogenic callus formation ranged from 61.52 to 75.22 on MS and it was lower on N6 42.26 to 67.67 (Table 1). Among the four different media composition, M2D2K2 (MS+1.5 mg/l 2,4-D + 0.3mg/l kin + 30g/l maltose) recorded the highest callus induction percentage of 99.10 (Table 2). Auxin especially 2,4- D in the range of $1-3 \mathrm{mg} / \mathrm{l}$, is essential for embryogenic callus induction from cereal embryos (Bhaskaran and Smith, 1990). The result of this study showed, there was no response in any of the genotypes in the absence of 2,4-D. There was no callus induction with out $2,4-\mathrm{D}$ reported 
Table 3. Organogenesis per cent from callus of immature embryo at various levels of hormones.

\begin{tabular}{|c|c|c|c|c|c|c|c|c|c|c|}
\hline Genotypes & $\mathbf{R}_{1}$ & $\mathbf{R}_{\mathbf{2}}$ & $\mathbf{R}_{\mathbf{3}}$ & $\mathbf{R}_{4}$ & $\mathbf{R}_{5}$ & $\mathbf{R}_{6}$ & $\mathbf{R}_{7}$ & $\mathbf{R}_{8}$ & $\mathbf{R}_{\mathbf{9}}$ & Mean \\
\hline$\left(\mathrm{G}_{1}\right) \mathrm{UMI} 757$ & 35.10 & 38.16 & 43.12 & 45.86 & 44.63 & 45.12 & 65.35 & 96.03 & 61.38 & 52.75 \\
\hline (G2) UMI 615 & 18.17 & 19.00 & 22.59 & 33.26 & 40.17 & 43.16 & 61.32 & 93.52 & 59.12 & 43.37 \\
\hline$\left(\mathrm{G}_{3}\right)$ UMI 112 & 22.52 & 24.38 & 25.13 & 35.28 & 43.62 & 44.38 & 62.37 & 94.12 & 60.78 & 45.84 \\
\hline$\left(\mathrm{G}_{4}\right) \mathrm{COH}(\mathrm{M}) 5$ & 40.18 & 44.17 & 48.38 & 50.93 & 52.15 & 52.38 & 70.38 & 98.17 & 67.15 & 58.21 \\
\hline$\left(\mathrm{G}_{5}\right) \mathrm{UMI} 285$ & 38.13 & 40.52 & 42.47 & 48.93 & 51.11 & 46.31 & 67.58 & 96.30 & 63.87 & 55.02 \\
\hline (G6) $\mathrm{CO} 1$ & 14.18 & 16.68 & 18.54 & 32.15 & 39.12 & 42.75 & 60.23 & 89.82 & 59.04 & 41.39 \\
\hline Mean & 28.05 & 30.49 & 33.37 & 41.06 & 45.13 & 45.68 & 64.54 & 94.58 & 61.89 & 49.43 \\
\hline Treatments & $\mathbf{R}_{1}$ & $\mathbf{R}_{\mathbf{2}}$ & $\mathbf{R}_{\mathbf{3}}$ & $\mathbf{R}_{\mathbf{4}}$ & $\mathbf{R}_{\mathbf{5}}$ & $\mathbf{R}_{6}$ & $\mathbf{R}_{\mathbf{7}}$ & $\mathbf{R}_{8}$ & $\mathbf{R}_{\mathbf{9}}$ & Mean \\
\hline$\left(\mathrm{G}_{1}\right) \mathrm{UMI} 757$ & 36.58 & 37.94 & 48.06 & 49.13 & 50.37 & 62.12 & 60.20 & 73.15 & 62.09 & 53.29 \\
\hline (G2) UMI 615 & 28.52 & 28.41 & 30.90 & 34.40 & 40.58 & 50.14 & 51.34 & 64.73 & 56.13 & 42.79 \\
\hline$\left(\mathrm{G}_{3}\right)$ UMI 112 & 30.18 & 33.72 & 39.27 & 42.05 & 44.55 & 54.13 & 56.58 & 70.65 & 57.15 & 47.58 \\
\hline$\left(\mathrm{G}_{4}\right) \mathrm{COH}(\mathrm{M}) 5$ & 36.13 & 41.24 & 53.46 & 54.52 & 57.74 & 65.14 & 66.17 & 81.16 & 68.13 & 58.18 \\
\hline$\left(\mathrm{G}_{5}\right) \mathrm{UMI} 285$ & 39.35 & 40.32 & 51.60 & 52.04 & 52.30 & 64.19 & 65.08 & 77.28 & 67.15 & 56.59 \\
\hline (G6) CO 1 & 20.10 & 20.18 & 25.12 & 28.13 & 38.12 & 48.13 & 50.18 & 60.28 & 54.12 & 38.26 \\
\hline Mean & 31.81 & 33.64 & 41.40 & 43.37 & 47.28 & 57.30 & 58.25 & 71.20 & 60.79 & 49.45 \\
\hline
\end{tabular}

by (Sumathi, 1992). Addition of 2,4-D induced callus development and the presence of 2,4-D in the culture medium was critical for callus induction from maize and formation of embryogenic callus. Addition of 1.5 $\mathrm{mg} / 1$ 2,4-D was found to induce good callus growth in MS medium. Ansari (1997) reported that $1.5 \mathrm{mg} / 1$ 2,4-D with $0.3 \mathrm{mg} / \mathrm{l} \mathrm{Kn}$ gave maximum embryogenic callus induction. These findings were similar to those reported by (Ansari, 1997; Wenbin et al., 2002; Al-Abed et al., 2006 and Binott et al., 2008). Immature embryos can initiate two types of callus cultures from their scutellar surfaces. Type I and Type II callus. Type I is compact and organogenic and easily obtained from immature embryo. On the other hand, Type II is friable and embryogenic and is initiated at a lower frequency than Type I (Carvalho et al., 1997). Only a few tropical genotypes have been shown to be capable of initiating Type II callus (Odour et al., 2006). Type II callus has been found to be more regenerable than Type I callus (Omer et al., 2008). Mixture of type I and type II calli was observed in $\mathrm{COH}(\mathrm{M}) 5$. Among the six maize genotypes investigated in this study, hybrid $\mathrm{COH}(\mathrm{M}) 5$ yielded the highest frequency $(99.10 \%)$ of embryogenic callus formation was recorded in MS medium with 2,4-D, kinetin and maltose. These genotypic variations may be attributed to differences in the components and the concentrations of the endogenous plant hormones and sensitivity to 2,4-D between genotypes as reported by (Agrawal et al., 2006) and Katiyar et al., 1999 also concluded that callus induction and plant regeneration were found to be greatly influenced by the genotypes and 2,4-D concentrations in media.

Regeneration: Maize plant regeneration can take place through two avenues viz., organogenesis or somatic embryogenesis. Organogenesis involves the formation of organs (shoot and root) directly from the explants, or indirectly via callus formation on the other hand, somatic embryogenesis involves the formation of scutella like structures from the explants or callus (Slater et al., 2004). Somatic embryogenesis is the most common avenue of plant regeneration (Odour et al., 2006). The embyogenic callus when allowed to grow in regeneration medium, it passes through organogenic stages until it reaches plantlet stage. This helps in the recovery of highly developed plantlets. Embryogenic callus was transferred to regeneration medium which contains MS medium with $30 \mathrm{~g} / \mathrm{l}$ sucrose for three weeks. Later, these calli transferred to fresh medium for subculture. Organogneic response from immature embryo revealed highly significantly differences. The range for this trait among genotypes was from 41.39 (\%) (Co1) to $58.21(\%)(\mathrm{COH}(\mathrm{M}) 5)$. The treatment R8 $(1.5 \mathrm{mg} / \mathrm{l} \mathrm{BAP}+0.2 \mathrm{mg} / \mathrm{l} \mathrm{NAA}+1.0 \mathrm{mg} / \mathrm{l} \mathrm{kn})$ showed significance $(94.58 \%)$ followed by R7 $(64.54 \%)$, R9 
(61.89\%) (Table 3). The treatment R1 (0.5 mg/l BAP + $0.1 \mathrm{mg} / \mathrm{l} \mathrm{NAA}+1.0 \mathrm{mg} / \mathrm{l} \mathrm{kn}$ ) showed poor performance $(28.05 \%)$. In this study, BAP $(0.5,1.0$ and $1.5 \mathrm{mg} / \mathrm{l})$, NAA $(0.1,0.2$ and $0.3 \mathrm{mg} / \mathrm{l})$ and kinetin $(1.0 \mathrm{mg} / \mathrm{l})$ were used for plant regeneration. When the effect of BAP was studied on organogenesis it was observed that high levels of BAP $(1.5 \mathrm{mg} / \mathrm{l})$ combined with low levels of NAA $(0.2 \mathrm{mg} / \mathrm{l})$ in MS medium containing $1.0 \mathrm{mg} / \mathrm{l} \mathrm{kinetin}$, induced highest regeneration per cent in immature embryo derived calli. The capacity of plantlet regeneration did not correlate with propensity for callus induction or somatic embryo formation, since not all embryogenesis calli were converted in to plantlets. When organogenic callus were transferred to regeneration media, their surfaces turned green within the one week and plantlet regeneration occurred within 21 days (Binott et al., 2008). When the effect of BAP, NAA and Kinetin was studied on the duration of organogenesis, lower concentration created speed lock, where the organ formation was delayed. The treatment $\mathrm{R} 8$ (1.5 mg/l BAP + $0.2 \mathrm{mg} / \mathrm{l} \mathrm{NAA}+1.0 \mathrm{mg} / \mathrm{l} \mathrm{kinetin})$ recorded earlier duration 17.99 days, while the treatment $\mathrm{R} 1(0.5 \mathrm{mg} / \mathrm{l} \mathrm{BAP}+0.1 \mathrm{mg} / \mathrm{l} \mathrm{NAA}+1.0 \mathrm{mg} / \mathrm{lkn})$ recorded later duration (19.39) days for organogenesis. Genotype plays an important role in tissue culture response across crop plants. Among the genotypes, the maximum regeneration percentage of plantlets was observed in COH(M) 5 G4 (58.18\%) followed by UMI 285 (G5) $(56.59 \%)$ (Table 4) Fig1. The interaction effect, G4R8 recorded the maximum value of $81.16 \%$ followed by G5R8 (77.28\%). The three genotypes, $\mathrm{COH}(\mathrm{M}) 5$, UMI 285 and UMI 757 were capable of giving quick and better organogenesis. This may be due to its innate capacity for regeneration. The higher regeneration per cent could be due to the use of suitable genotype and the appropriate tissue source used for the embryogenic calli induction and regeneration. Genotype plays an important role in tissue culture response across crop plants. Bohorova et al., 1995 reported genotype dependent regeneration response among tropical and subtropical maize lines. Immature embryo derived callus showed the highest response of regeneration, because immature embryo contained sufficient amount of endogenous hormones for totipotency reported by Shohael et al., (2003).

\section{Conclusion}

The regeneration method reported here is quick, efficient and highly reproducible and could be perhaps used in transformation studies. The four genotypes $\mathrm{COH}(\mathrm{M}) 5$, UMI 757, UMI 112 and UMI 285 were identified in this study as gave good callus induction and regeneration response. Since the hybrid had greater regeneration capacities than inbreds. The successful regeneration of some of the inbred line and hybrids provide a basis for development of genetic transformation to improve priority traits such as enhanced pest and drought tolerance.

\section{REFERENCES}

Abebe, Z.D., Teffera, W. and Machuka, J.S. (2008). Regeneration of tropical maize lines (Zea mays L.) from mature zygotic embryo through callus initiation. African Journal of Biotechnology, 7: 2181-2186.

Agrawal, P.K., Gosal, S.S. and Sidhu, G.S. (2006). Sequential reduction of 2, 4-D improves whole plant regeneration from long term maintained calli in some indica cultivars of rice. Oryza, 43: 10-15.

Aguado - Santacruz, G.A., Moya, E.G., Acuna, J.L.A., Gomez, B.M., Moya, E.S., Ortiz, E.R.P., Bremont, J. F.J. and Cruz, Q.R. (2007). In vitro plant regeneration from quality Protein Maize. In vitro Cell. Dev. Biol., 43: 215-224.

Ahmadabadi, M., Ruf, S. and Bock, R. (2007). A leaf based regeneration and transformation system for maize (Zea mays L.). Transgenic Res., 16: 437-448.

Al-Abed, D., Rudrabhatla, S., Talla, R. and Goldman, S. (2006). Split-seed: a new tool for maize researchers. Planta, 223: 1355-1360.

Ansari, N.A. (1997). Tissue culture studies in maize (Zea mays L.) Ph.D. (Ag.) Thesis, TNAU, Coimbatore.

Barloy, D. and Beckert, M. (1993). Improvement of regeneration ability of androgenetic embryos by early anther transfer in maize plant. Plant Cell Tissue Organ Cult., 33: 45-50.

Bhaskaran, S. and Smith, R.A. (1990). Regeneration in cereal tissue culture a review. Crop Sci., 30: 1328-1336.

Binott, J.J., Songa, J.M., Ininda, J., Njagi, E.M. And Machuka, J.(2008). Plant regeneration from immature embryos of Kenyan maize in bread lines and their respective single cross hybrids through somatic embryogenic. African Journal of Biotechnology, 7: 981-987.

Bohorova, N.E., Luna, B., Brito, R.M., Huerta, L.D. and Hoisington, D.A. (1995). Regeneration potential of tropical, substropical, medaltitude and highland maize inbreds. Maydica, 40: 275-281.

Carvalho, C.H.S., Bohorova, N., Bordallo, P.N., Abreu, L.L., Valicente, F.H., Bressan, W. and Paiva, E. (1997). Type II callus production and plant regeneration in typical maize genotypes, Plant Cell Rep., 17: 73-76.

Danson, J.W., Lagat, M. and Mbogori, M. (2006). Screening tropical maize lines for the production and regeneration of friable and embryogenic type II callus. African Journal of Biotechnology, 5: 2367-2370.

Duncan, D.R., Williams, M.E., Zehr, B.E. and Widholm, M. (1985). The production of callus capable of plant regeneration from immature embryos of numerous $\mathrm{Zea}$ mays genotypes. Planta, 165: 322-332.

Duvick, D.N. (1998). Crop improvement: emerging trends in maize. In: Crop productivity and sustainability. Shaping the future. Oxford and IBH publishing co., New Delhi, pp: 127-138.

FAO,(2009). FAOSTAT.Food and Agricultural Organization retrieved from http://faostat.fao.org

Furini, A. and Jewell, D.C. (1994). Somatic embryogenesis and plant regeneration from immature embryos of tropical and subtropical Zea mays L. genotypes. Maydica, 39: 155-164.

Gomez, K.A. and Gomez, A.A. (1984). Statistical procedures for Agricultural Research. John Wiley and Sons. Inc., New York. 680.

Gordon-Kamm, W., Dilkes, B.P., Lowe, K., Hoerster, G., Sun, X., Ross, M., Church, K.D., Bunde, C., Farell, J., 
Maddock, S., Snyder, J., Skyes, L., Li, Z., Woo, Y. M., Bidney, D. and Larkins, B.A. (1990). Stimulation of the Cell cycle and maize transformation by disruption of the plant retinoblastoma path way. Proc. Natl. Acad. Sci., USA, 99: 11975-11980.

Green, C.E. and Philips. R.C. 1975. Plant regeneration from tissue cultures of maize. Crop Sci., 15: 417-421.

Huang, X.Q and Wei. Z.M. (2004). High frequency plant regeneration through callus initiation from mature embryos of maize. Plant Cell Rep., 22: 793-800.

Ishida, Y., Saito, S.H., Ohta, S., Hiei, Y., Komari, T. and Kumashiro, T. (1996). High efficiency transformation of maize (Zea mays L.) mediated by Agrobacterium tumefaciens. Nature Biotech., 14: 745-750.

Katiyar, S. K., Chandel, G., Singh and Pratibha., R. (1999). Genetic variation and effect of 2,4-D on in vitro plant regeneration in indica rice cultivars. Oryza, 36: 254-256.

Koziel, M., Beland, G.I., Desai, N., Hill, M., Kadwell, S., Launis, K., Lewis, K., Maddox, D., Pherson, K., Meghji, M., Merlin, M., Rhodes, R., Warren, G.W., Wright, M. and Evolas, S. (1993). Field performance of elite transgenic maize plant expressing an insectisidal protein derived from Bacillus thuringiensis. Biol. Tech., 11: 194-200.

Machuka, J.S. (2001). Agricultural Biotechnology for Africa. Africa scientists and farmers must feed their own people. Plant Physiol., 126: 16-19.

Manivannan, A., Kaul, J., Singode, A. and Dass, S. (2010). Callus induction and regeneration of elite Indian maize inbreds. African Journal of Biotechnology, 9(44): 7446-7452.

Morocz, C., Donn, G., Nemeth, J. and Dudits, D. (1990). An improved system to obtain fertile regenerants via maize protoplast isolated from highly embryogenic suspension culture. Theor. Appl. Genet., 80: 712-726.

Murashige, T. and Skoog, F. (1962). A revised medium for rapid growth and bioassay with tobacco tissue cultures. Physiol. Plantarum., 15: 473-497.

Odour, R.O., Njagi, E.N.M., Ndung'u, S. and Machuka, J.S. (2006). Invitro regeneration of Dryland Kenyan Maize Genotypes through somatic embryogenesis. International Journal of Botany, 2: 146-151.

Omer, R.A., Ali, A.M., Matheka, J.M. and Machuka, J.
(2008). Regeneration of Sudanese maize in bred lines and open pollinated varieties. African Journal of Biotechnology, 7: $1759-1764$.

Pareddy, D.R. and Petolino, J.F. (1990). Somatic embryogenesis and plant regeneration from immature inflorescence of several elite inbreds of maize. Euphytica, 67: 211-219.

Pingali, P.L. and Pandy, S. (2001). Meeting world maize needs: Technological Opportunities and priorities for the public sector. In: CIMMYT. 1999 - 2000. World Maize Facts and Trends, Mexico. Pp. 1-20.

Rakshit, S.Z. Rashid, J.C. Sekhar, Fatma, T. and Das. S. (2010). Callus induction and whole plant regeneration in elite Indian maize (Zea mays L.) inbreds. Plant Cell Tissue Organ cult. 100: 31-37.

Rooz, BBK. (2002). Plastid transformation in maize: construction and testing of vector, dissertion, Post Graduate School, Indian Agricultural Research Institute, New Delhi, India.

Sairam, R.V., Paran, M., Franklin, G., Lifeng, Z., Smith, B., Macdougall, J., Wilber, C., Sheikhi, H., Meeker, N., Al-Abed, D., Berry, K., Vierling, R. and Goldman, S.L. (2003). Shoot meristem an ideal explants for Zea mays $L$. transformation. Genome, 46: 323-329.

Shohael, A.M., Akanda, M.A.L., Parvez, S. and Mahfuja, S. (2003). Somatic embryogenesis and plant regeneration from immature embryo derived callus of inbred maize (Zea mays L.). Biotech., 2: 154-161.

Slater, A., Scott, N.W. and Fowler, M.R. (2004). The genetic manipulation of plants. Oxford University Press Inc. N. Y., USA, Plant biotechnology : 35-52.

Sumathi, R. (1992). Studies on callus organization and in vitro organogenesis in rice (Oxyza sativa L.) M.Sc., (Ag.) Thesis, TNAU, Coimbatore.

Vladimir, S., Gilberton, L., Adae, P. and Duncan, D. (2006). Agrobacterium mediated transformation of seedling-derived maize callus. Plant cell Rep., 25: 320-328.

Wenbin, L., Masilamany, P., Kasha, K.J. and Pauls, P. (2002). Development, tissue culture and genotypic factors affecting plant regeneration from shoot apical meristem of germinated Zea mays seedlings. In vitro cellular and Developmental Biology. 38: 285-292. 